\title{
Patterns of Gene Expression Reveal a Temporally Orchestrated Wound Healing Response in the Injured Spinal Cord
}

\author{
Margaret J. Velardo, ${ }^{1,4,5,6}$ Corinna Burger, ${ }^{2,4,5,6}$ Philip R. Williams, ${ }^{1,4}$ Henry V. Baker, ${ }^{2,4,5,6}$ M. Cecilia López, ${ }^{2,5,6}$ \\ Thomas H. Mareci, ${ }^{3,4}$ Todd E. White, ${ }^{1,4}$ Nicholas Muzyczka, ${ }^{2,4,5,6}$ and Paul J. Reier ${ }^{1,4,5}$ \\ ${ }^{1}$ Department of Neuroscience, ${ }^{2}$ Department of Molecular Genetics and Microbiology, ${ }^{3}$ Department of Biochemistry and Molecular Biology, ${ }^{4} \mathrm{McKnight}$ \\ Brain Institute, ${ }^{5}$ Powell Gene Therapy Center, and ${ }^{6}$ UF Genetics Institute, College of Medicine, University of Florida, Gainesville, Florida 32610
}

\begin{abstract}
Spinal cord injury (SCI) induces a progressive pathophysiology affecting cell survival and neurological integrity via complex and evolving molecular cascades whose interrelationships are not fully understood. The present experiments were designed to:(1) determine potential functional interactions within transcriptional expression profiles obtained after a clinically relevant SCI and (2) test the consistency of transcript expression after SCI in two genetically and immunologically diverse rat strains characterized by differences in T cell competence and associated inflammatory responses. By interrogating Affymetrix U34A rat genome GeneChip microarrays, we defined the transcriptional expression patterns in midcervical contusion lesion sites between 1 and $90 \mathrm{~d}$ postinjury of athymic nude (AN) and Sprague Dawley (SD) strains. Stringent statistical analyses detected significant changes in 3638 probe sets, with 80 genes differing between the AN and SD groups. Subsequent detailed functional categorization of these transcripts unveiled an overall tissue remodeling response that was common to both strains. The functionally organized gene profiles were temporally distinct and correlated with repair indices observed microscopically and by magnetic resonance microimaging. Our molecular and anatomical observations have identified a novel, longitudinal perspective of the post-SCI response, namely, that of a highly orchestrated tissue repair and remodeling repertoire with a prominent cutaneous wound healing signature that is conserved between two widely differing rat strains. These results have significant bearing on the continuing development of cellular and pharmacological therapeutics directed at tissue rescue and neuronal regeneration in the injured spinal cord.
\end{abstract}

Key words: spinal cord; microarray; gene expression; transcriptional profiling; injury; extracellular matrix; inflammation; T cells; degeneration; regeneration; contusion; magnetic resonance

\section{Introduction}

Blunt force trauma to the spinal cord (SC) triggers intricate molecular and cellular responses that progressively transform a bruise to a region of extensive tissue degeneration having devastating functional consequences (for review, see Velardo et al., 2000). Deciphering the molecular events underlying this pathology is challenging because of inherent difficulties in determining functional interrelationships between multiple genes operating over a wide temporal-spatial spectrum (Bareyre and Schwab, 2003). In addition, traditionally, the biochemical events of CNS damage and regeneration have been addressed primarily within the context of neurobiology. As a result, the existence of common

Received Aug. 12, 2004; revised Aug. 16, 2004; accepted Aug. 16, 2004.

MR images were obtained in the Advanced Magnetic Resonance Imaging and Spectroscopy Facility at the McKnight Brain Institute. We are grateful to M. Smith, T. Klocker, W. Stone, J. Blundell, H. Norton, K. Siegel, and K. Spaulding for their assistance; T. Black for providing custom MR image processing-analysis software; and M. F. Overstreet Endowment, State of Florida Brain and Spinal Cord Research Trust Fund, National Institute of Neurological Disorders and Stroke (P01-NS36302), and National Institutes of Health (P41 RR16105, R01 NS42075) for funding.

Correspondence should be addressed to Dr. Margaret J. Velardo, Department of Neuroscience, McKnight Brain Institute of the University of Florida, Box 100244, Gainesville, FL 32610-0244. E-mail: velardo@mbi.ufl.edu. DOI:10.1523/JNEUROSCI.3316-04.2004

Copyright $\odot 2004$ Society for Neuroscience $\quad$ 0270-6474/04/248562-15\$15.00/0 mediators and mechanisms of injury between non-neural and neural cells, the significance of their interactions, and the resultant impact on injury and endogenous repair responses may have been underestimated.

Recent studies have suggested that damage and repair processes observed in other organ systems play a more fundamental role in spinal cord injury (SCI) than previously appreciated. For example, inflammatory (Hausmann, 2003) and vascular repair processes (Mautes et al., 2000; Casella et al., 2002; Loy et al., 2002; Noble et al., 2002) have been demonstrated after SCI. When these observations are considered along with other postinjury phenomena including fibro-glial scarring (Reier, 1986; Fawcett and Asher, 1999; Fitch et al., 1999), extracellular matrix (ECM) changes (McKeon et al., 1999; Lemons et al., 2001; Bradbury et al., 2002; Tang et al., 2003), contusion fibrosis (Inman et al., 2002; Sroga et al., 2003), and transforming growth factor (TGF) and fibroblast growth factor expression (Koshinaga et al., 1993; Logan and Berry, 1993; Lagord et al., 2002), the emerging picture suggests that SCI invokes a more generalized wound healing-like response that is coupled with neural-specific processes (Hill et al., 2003).

Dermal wound healing $(\mathrm{WH})$ has unique characteristics rela- 
tive to WH in other organs and is a highly orchestrated molecular and cellular process characterized by sequential, but overlapping, stages of hemostasis, inflammation, proliferation, and remodeling at specific postinjury times (Clark, 1993; Martin, 1997; Witte and Barbul, 1997; Singer and Clark, 1999). If SCI and cutaneous WH operate by analogous mechanisms, it would be expected that both processes would use the same gene families, and they would exhibit similarly coordinated temporal expression patterns. Accordingly, one objective of this study was to analyze the proposed parallel between SCI and dermal WH by constructing a functionally defined microarray database after a clinically relevant SCI in Sprague Dawley (SD) rats.

Because of increased awareness of the need for preclinical injury models in neurotrauma research that accurately reflect human biology, greater emphasis is being placed on intraspecies and interspecies experimental comparisons (Kleitman, 2004; Reier, in press). Therefore, another aim of this study was to compare transcriptional expression patterns in two genetically diverse rodent strains [i.e., commonly used SD rats in comparison with athymic nude (AN) rats that have substantially reduced levels of functional T cells (Rolstad, 2001)]. The AN strain was chosen based on our previous observations that (1) postcontusion behavioral recovery patterns differed between SD and AN rats with comparable spinal injuries, and (2) relevant to our WH hypothesis, AN rats exhibit decreased fibrosis and cutaneous scarring after spinal surgery in comparison to SD rats (data not shown). The AN rat model is relevant to SCI because inflammation is a primary component of WH and CNS injury, and autoreactive T cells have been reported to promote secondary tissue damage in some studies (Popovich et al., 1996; Huang et al., 1999; Jones et al., 2002, 2004) and exhibit neuroprotective properties in others (Kipnis et al., 2002; Schwartz and Hauben, 2002).

To accomplish these objectives, we used Affymetrix U34A rat genome GeneChip microarray technology, which permits the examination of thousands of neural and non-neural genes and large sample numbers over multiple post-SCI intervals in conjunction with histology and magnetic resonance (MR) microimaging. This approach proved to be a powerful way to correlate the dynamic changes in morphology with functionally defined gene expression profiles from 1-90 d after SCI. Our analysis revealed an intricate postinjury transcriptional response with significant changes in the expression levels of 3638 probe sets that possessed an overall pattern remarkably resembling the molecular events underlying the stages of dermal WH (Velardo et al., 2003).

\section{Materials and Methods}

Spinal contusions

Female adult (220-250 gm) Sprague Dawley (Hsd:SD) or athymic nude (Hsd:RH-rnu/rnu) rats (Harlan, Indianapolis, IN) received $\mathrm{C}_{4,5}$ midline contusions using the New York University impactor (10 gm; $12.5 \mathrm{~mm}$ height), as described by el-Bohy et al. (1998), and postoperative care four times per day for 4-10 d, as detailed by Schrimsher and Reier (1992).

\section{Tissue preparation for histology and MR microimaging}

Two separate groups of animals were used for this part of the experiments, one group for histology and one for MR microimaging (supplemental material, available at www.jneurosci.org). Deep anesthesia (0.6 $\mathrm{ml} / \mathrm{kg}$; Beuthanasia-D Special, Burns-Biotic Laboratories, Omaha, NE) was used for all perfusion procedures. Rats were transcardially perfused with ice-cold $0.9 \%$ saline containing $0.2 \mathrm{U} / \mathrm{ml}$ heparin and $0.002 \%$ $\mathrm{NaNO}_{3}$, followed by $4 \%$ paraformaldehyde (PF) fixative for immunofluorescence and MR microimaging and 4\% PF-2\% glutaraldehyde for plastic histology. After $24 \mathrm{hr}$, SCs were removed and postfixed overnight. For immunofluorescence, transverse vibratome sections $(40 \mu \mathrm{m})$ were cut from blocked tissue. For ultrathin plastic sections, fixed tissue blocks
$1 \mathrm{~mm}$ in size were embedded in Epon-Araldite, cut transversely at $2 \mu \mathrm{m}$, and stained and mounted as described by Schrimsher and Reier (1992). For MR microimaging, SCs were left intact, washed in PBS overnight, and placed in spectroscopy-grade glass tubes (Wilmad, Buena, NJ).

Immunofluorescence. Free-floating sections were incubated in $10 \%$ normal goat blocking serum (NGS) (Jackson Immunoresearch, West Grove, PA) with Triton X-100 in $1 \times$ PBS for $1 \mathrm{hr}$ at room temperature (RT). Sections were incubated with $1^{\circ}$ antibodies overnight at $4^{\circ} \mathrm{C}$ at the following dilutions: anti-heat shock protein (HSP) 72/73 (1:50; Oncogene, San Diego, CA), anti-vimentin (1:10,000; Sigma, St. Louis, MO), anti- $\alpha$-smooth muscle actin (1:400,000; Sigma), anti-IGF-I (1:4000; Peninsula, Torrance, CA), and anti-glutathione $S$-transferase (GST)- $\mu$ (1:1000; Acris $\mathrm{GmbH}$, Hiddenhausen, Germany); $2^{\circ}$ antibodies were conjugated to Alexa Fluor 488 diluted in 5\% NGS and were incubated for $1 \mathrm{hr}$ at RT (1:500; Molecular Probes, Eugene, OR). Vimentin immunolabeling required a secondary biotin-streptavidin (1:400; Vector Laboratories, Burlingame, CA) conjugated to Alexa Fluor 488 (Molecular Probes) detection system in 5\% NGS, for $1 \mathrm{hr}$ each incubation. Slides were coverslipped with Vectashield (Vector Laboratories). An Olympus Optical (Melville, NY) IX-70 inverted microscope attached to the Bio-Rad (Hercules, CA) MRC 1024 confocal system was used for photomicrographs.

MR microimaging. MR images were acquired at $600 \mathrm{MHz}$ with a 14.1 tesla Bruker Avance imaging spectrometer (Bruker NMR Instruments, Billerica, MA) with a multiple-slice spin echo pulse sequence using a repetition time of $2500 \mathrm{msecs}$, an echo time of 20 msecs, and eight averages. The specimen tube was inserted into a cylindrical MR saddleshaped volume coil ( $6 \mathrm{~mm}$ in diameter and $15 \mathrm{~mm}$ in length) with the lesion centered in the coil. Multiple consecutive $0.2 \mathrm{~mm}$ slice image sets were acquired in transverse, sagittal, and longitudinal orientations. Transverse images were acquired with a $5 \times 5 \mathrm{~mm}$ field-of-view into a matrix of $256 \times 256$ data points with 60 slices covering $12 \mathrm{~mm}$ in the rostral-to-caudal direction. Sagittal and longitudinal images were acquired with a $20 \times 5 \mathrm{~mm}$ field-of-view into a matrix of $1024 \times 256$ data points with 20 slices covering $4 \mathrm{~mm}$ sagittal and coronal directions. Lesion volume measurements for each SC were taken from the transverse multiple-slice data set and analyzed with KS400 software (Carl Zeiss, Thurmwood, NY) calibrated to convert pixels ${ }^{2}$ into micrometers ${ }^{2}$. Tissue pathology was manually outlined in each image. Lesion volumes for 26 cords were calculated by multiplying the lesion area by the slice thickness to determine slice volume, then summing slice volumes. MR relaxation times were measured in five cords $(1,3,10,30$, and $90 \mathrm{~d}$ post injury) using transverse images, but with 11 slices of $0.5 \mathrm{~mm}$ thickness spaced 1 $\mathrm{mm}$ apart. Longitudinal relaxation times, $T_{1}$, were measured with a progressive saturation spin echo sequence with repetition times of 275, 500, 1000,2000 , and 5000 msecs with an echo time of 15 msecs. Transverse relaxation times, $T_{2}$, were measured with a spin echo sequence using a repetition time of 2500 msecs and echo times of 15, 30, 45, 60, and 90 msecs. All MR images and relaxation times were processed and analyzed with custom software written in Interactive Data Language (Research Systems, Boulder, CO).

\section{Preparation of test RNAs for microarray analysis}

A third group of animals was used to interrogate Affymetrix (Santa Clara, CA) GeneChips and were killed at 1, 3, 10, 30, and $90 \mathrm{~d}$ after injury (supplemental material, available at www.jneurosci.org). SCs were surgically re-exposed and spinal tissue including dura and meninges was dissected into lesion, rostral, and caudal blocks under RNAase-free conditions, as depicted in the supplemental material (available at www. jneurosci.org). Samples were placed into RNAlater (Ambion, Austin, TX) until RNA extraction. Tissue was homogenized in $1.5 \mathrm{ml}$ of Trizol (Invitrogen, Carlsbad, CA), and RNA was isolated following manufacturer's instructions. An average of $100 \mu \mathrm{g}$ of RNA was obtained from $100-150 \mathrm{mg}$ of tissue pooled from four animals. After quantification, half of the sample was further purified using RNEasy miniprep columns (Qiagen, Valencia, CA), following the manufacturer's instructions for RNA cleanup. At this point, RNA from the rostral and caudal blocks was frozen. All the subsequent procedures were done following the Affymetrix technical manual and used lesion block material. Five micro- 
grams of total RNA were used. Each U34A rat genome GeneChip (Affymetrix) was interrogated with material pooled from four animals, and each time point was replicated at least three times with material originating from different animals, making the data from each array truly independent biological replicates.

Summary of chip quality control parameters, normalization, and analysis methods of GeneChips. Scanned images (*.dat files) were analyzed with Affymetrix Microarray Suite v5.0. Raw $Q$ values ranged from 1.6 to 4.2. Average background ranged from 56 to 124 . Chips were normalized using global normalization with an average target gene intensity of 500. Scaling factors ranged from 1.9 to 11.1, indicating an acceptably narrow range of overall signal intensity among the chips used in these studies. Raw data files can be found at http:// users.mbi.ufl.edu/velardo.

Expression filter. Probe sets that were flagged as absent on all arrays analyzed in this study by the Affymetrix Microarray Suite v5.0 software using default settings were removed from the datasets subjected to hierarchical cluster analysis and significance analysis of microarrays (SAM) analysis (Tusher et al., 2001). After this expression filter was applied, the dataset was reduced from 8799 probe sets to 5884 probe sets.

Unsupervised analysis. For unsupervised analysis, the dataset was passed through a variation filter to remove probe sets whose hybridization signal intensities did not vary much across the data set. By ranking on coefficient of variation, the top half of the dataset (observation of 2942 probe sets) was identified and subjected to hierarchical analysis.

Cluster analyses. K-means and hierarchical cluster analyses were performed using variance normalized data in which the mean was normalized to 0 and the SD to 1 and viewed with the algorithms in the software packages Cluster and TreeView, developed by Eisen et al. (1998).

Supervised analysis. Probe sets whose hybridization signal intensities varied significantly across the dataset were identified using the program known as SAM, which performed modified $F$ tests on the cube root of the normalized Affymetrix Microarray Suite v5.0 signal intensity values. SAM used random permutations of the dataset to estimate the false discovery rate.

In this study, SAM was tuned to a false discovery rate of 0.05 . Accordingly, of the 3638 probe sets identified as significant, we estimate that 182 were identified in error, based on the permutation analysis.

Functional analysis of transcripts. Probe sets within the $10 \mathrm{~K}$-means clusters were subject to a comprehensive, detailed, six-level functional analysis, whereby identity was verified using GenBank accession number, aliases were compiled, and biochemical and biological functions were determined. After the identity of a probe set was confirmed, multiple internet bioinformatics and National Center for Biotechnology Information (NCBI) search engines, including PubMed searches, were used to assign its biological function within the injury context. The transcripts were then color coded and clustered by function in each bin. Basic local alignment search tool (BLAST)n searches were used to classify expressed sequence tags (ESTs). Probe sets without confirmed identities were placed in the "identity unknown" category. Probe sets that could be identified but that did not have an ascertainable function were classified as "function unknown." For details, see supplemental material (available at www.jneurosci.org).

\section{Results}

Overview of histological and MRI changes after cervical SCI in $\mathrm{SD}$ and $\mathrm{AN}$ rats

The first two groups of injured, sham, and control animals in this study were used for histological and MR microimaging studies to establish a quantitative and qualitative morphological perspective for our microarray analysis in terms of the temporal development and uniformity of these midcervical spinal contusion injuries (supplemental material, available at www.jneurosci.org). These lesions in both strains had an early phase of multifocal petechial hemorrhaging that progressed by $24 \mathrm{hr}$ to a more advanced stage of tissue edema and central gray-matter hemorrhagic necrosis with substantial, concomitant white-matter pathology (Quencer and Bunge, 1996; Velardo et al., 2000; Hulsebosch, 2002; Norenberg et al., 2004). Ultimately, areas of extensive tissue erosion began exhibiting zones of cavitation that by 1 month postinjury were evolving into continuous or parti- 

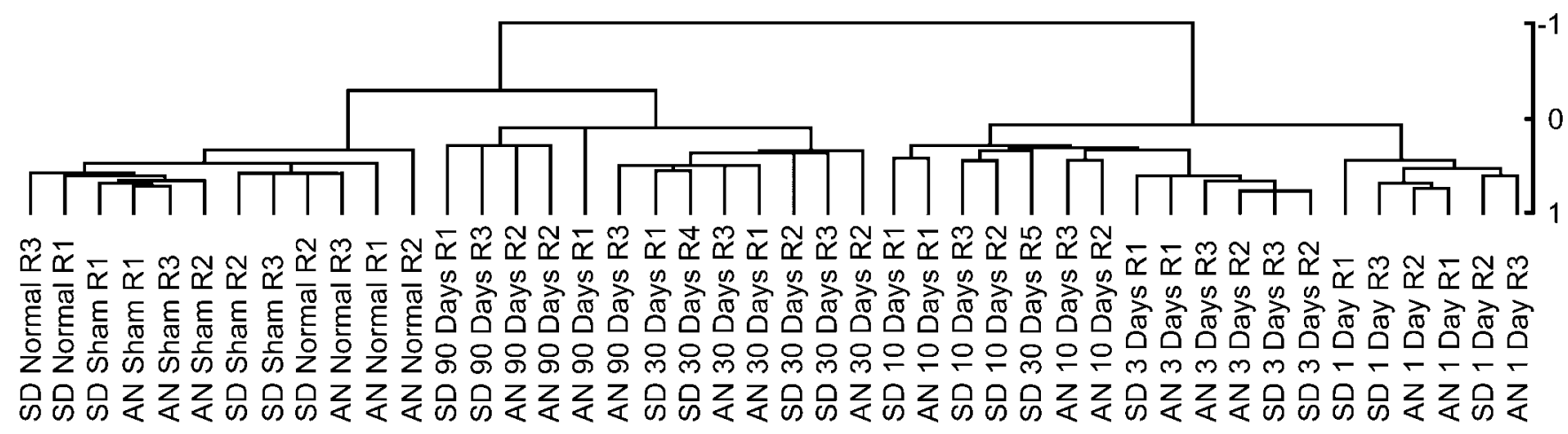

Figure 2. Unsupervised dendrogram depicting the degree of similarity between hybridization signal intensities of the 2942 probe sets that varied the most over the time course. The scale to the right shows the Pearson's correlation coefficient. The distance metric was 1 - Pearson's correlation coefficient.

tioned cysts (Fig. 1A). The cervical lesions also displayed the characteristic ellipsoid rostral-to-caudal configuration of contusion injuries, becoming more tapered and dorsally restricted over distance from the epicenter (Fig. $1 B$ ). Between 1 and 3 months postinjury, the lesions continued to cavitate with no overt differences seen between strains. The lesions were often bilaterally symmetrical in shape, although some more laterally biased injuries (Fig. $1 A, \mathrm{SD}$ at $10 \mathrm{~d}$ ) also were obtained. In addition, there was a noticeable reduction in the overall size of the spinal cord at the lesion epicenter (Fig. 1A, $90 \mathrm{~d} \mathrm{SD}$ and AN).

Serial-slice MR microimaging and subsequent MR volumetric analyses were performed to obtain a dynamic, three-dimensional perspective of the evolution of these lesions (Fig. $1 B, C$ ). At early time points (i.e., days 1, 3, and 10), the injury epicenter was defined by a highly intense (i.e., white) signal extending into SC white matter. In addition, small regions of hemorrhage or clotted blood were interspersed throughout the contusion site. These foci were of very low intensity [Fig. $1 B$, black contrast (e.g., AN and SD at $3 \mathrm{~d}$ )], resulting from the presence of iron (hemosiderin) (Hackney et al., 1986). Hyperintense white areas, apparently resulting from edema, became greatly reduced as the lesion continued to evolve, and multiloculated cysts appeared by 1 month. By day 90, areas of edema had completely resolved, and the cysts assumed a well delineated form that extended into the dorsal column of the white matter, both rostrally and caudally. Measurements of the contusion lengths made from serial MR microimages showed variability in the overall rostral-caudal extent of the lesions (data not shown); however, greater consistency was seen in lesion volumes within and between strains at 30 and $90 \mathrm{~d}$ (Fig. 1C). As seen in tissue sections (Fig. 1A), the lesion volume showed a gradual reduction over time (Fig. $1 B$ ).

\section{SAM reveals highly orchestrated temporal waves of gene expression that are conserved between strains after spinal injury}

To construct the transcriptional profile associated with the evolution of tissue changes in the contusion lesion and compare it in the two rat strains, a third group of animals $(n=128)$ was used to interrogate Affymetrix U34A rat genome GeneChips containing 5249 known genes and 3105 ESTs (supplemental material, available at www.jneurosci.org). The statistical analyses are detailed in Materials and Methods. We used both unsupervised and supervised analyses to assess the global transcriptional response to SCI. To eliminate noise in the dataset, we initially removed probe sets that were never detected above background on any of the arrays. We then applied a variation filter by ranking on the coefficient of variation of the probe sets across the dataset and selecting the top half of those whose hybridization signal intensities varied the most. The hybridization signal intensities were mean centered and the variance normalized to one before hierarchal clustering. Figure 2 depicts the resultant unsupervised dendrogram and illustrates that after SCI, experimental groups cluster in terms of injury status, replicates, and postinjury intervals, but not strain, thus demonstrating excellent reproducibility of the genomic response to SCI over time. The major node of separation distinguished the 1,3 , and $10 \mathrm{~d}$ postinjury time points from the preinjury, $30 \mathrm{~d}$, and $90 \mathrm{~d}$ intervals. Within the major nodes, subclustering occurred in accordance with postinjury time points. The dendrogram thus reveals a consistent, dynamic, and temporally organized pattern of change in genomic expression as a result of SCI that tends to return to the preinjury state over time.

To identify probe sets whose hybridization signal intensities varied as a function of post-SCI interval, we performed a supervised ANOVA using the algorithm implemented in SAM. SAM uses a modified $F$ test to identify significant probe sets and uses random permutations of the dataset to obtain an estimate of the false discovery rate of gene expression changes. Using SAM, 3638 significant probe sets were identified, and the estimated false discovery rate was tuned to $5 \%$, or 182 , of the significant probe sets. To permit visualization of the temporal patterns of gene expression represented by the 3638 significant probe sets, K-means clustering was used. The probe sets were organized into 10 bins or clusters (Fig. $3 A$ ) that revealed strikingly distinct expression patterns that corresponded with injury status and/or postinjury interval. Although neither the unsupervised analysis nor the $\mathrm{K}$-means clustering of significant probe sets identified major strain differences in the global gene expression patterns, there were individual transcripts that varied between the SD and AN animals. For clarity, we note here that stringent $t$ test comparisons $(p \leq 0.001)$ of the probe sets showed that 83 probe sets $(80$ transcripts) differed significantly between the strains overall (data not shown). However, the following results address only the similarities in transcripts and expression patterns between the strains.

\section{Establishment of a functionally based algorithm for analysis of gene expression patterns after contusion injury}

The distinctive organization of the K-means clusters by injury state and time after injury suggested that a highly coordinated pattern of transcript expression occurred in the aftermath of these contusion injuries. Therefore, to arrange the significantly changed genes into a functional framework, we researched their 


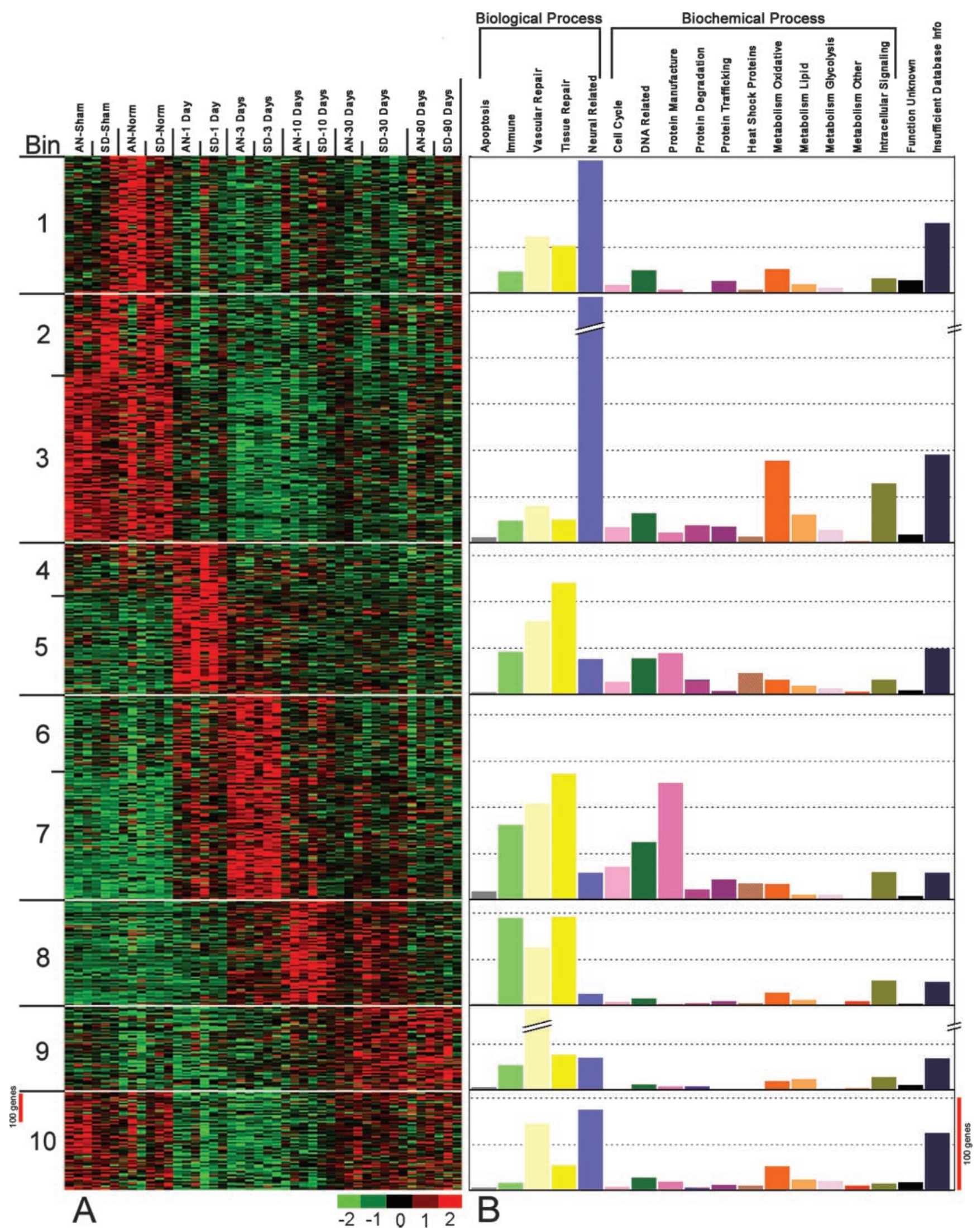

Figure 3. K-means clustering of 3638 transcript profiles (including 1489 EST probe sets) reveals temporally orchestrated, distinct waves of expression $(A, B)$. $A, A f t e r$ organization of genes by biological and biochemical functions, these temporal waves acquire unique molecular and functional identities. Gene expression profiles inferred by hybridization signal intensities of the various probe sets. Probe sets are shown in rows, and arrays are shown in columns. Variance-normalized gene expression levels are as indicated on the color scale; scale bar, 100 probe sets. B, Genes within each bin are functionally categorized (for method, see supplemental material, available at www.jneurosci.org) by biological or biochemical function. The height of the bars indicates the number of probe sets in each category (scale bar, 100 probe sets). Bins with similar expression patterns are combined (i.e., bins $2+3,4+5$, and $6+7$ ). Biological functions include apoptosis (gray), immune 
biological properties using multiple internet bioinformatics search engines, web sites, and NCBI resources including BLAST, online Mendelian inheritance in man, Entrez, PubMed, etc. (see Materials and Methods and the analytical paradigm summary in supplemental material, available at www.jneurosci.org). The collective results of those searches were then synthesized into a color-coded, mechanism-based map of gene expression (supplemental material, available at www.jneurosci.org) showing that a highly reproducible molecular program unfolds over time after SCI. Use of the information provided by that all-inclusive table enabled us to analyze the data further. First, we recorded the number of probe sets in each general function category to illustrate the relative dominance of each of the major biologicalbiochemical processes in the nonoperated, sham, and injured states depicted by the K-means clusters (Fig. 3B). Secondly, we further subclassified the major biological function-process categories into gene superfamilies or functional subgroups, tabulated the number of genes in each, and thereby obtained a synopsis of the major gene families that were involved in each process (Table 1). This yielded a succinct, intelligible picture of the unique functional signature of each postinjury interval, as well as demonstrating their interrelationships.

\section{Dynamic maintenance of form and function in normal spinal cord}

To form a basis for comparison with gene expression changes after injury, first we examined "normal" SC transcript expression in the K-means dataset. This displayed three basic expression patterns: (1) genes that are most highly expressed in the normal state (nonoperated controls), (2) genes in normal spinal cord that decrease in expression after sham surgery and contusion, and (3) genes expressed in normal and sham-operated rats that decrease in expression after contusion but return to being highly expressed at 30-90 d (Fig. 3A, Bins 1,2+3, and 10). With the exception of two unusual clusters of olfactory and pheromone receptor transcripts (supplemental material, available at www.jneurosci.org) that are highly expressed in normal but not sham-operated animals, the vast majority of normal SC genes are related to common neurotransmitters or their synthesizing enzymes, associated receptors, transporters, and signaling molecules (Table 1). An extensive number of transcripts are devoted to the establishment or maintenance of synapses and neural constituents, such as myelin, microtubule, neurofilament, and molecular motor families. The high energy requirement and membrane-rich character of the CNS are represented by numerous transcripts devoted to glucose, energy, and lipid metabolism (Table 1). Morphogenetic, polarity, or development gene families also are present, as are transcripts dedicated to suppression of cellular growth and induction of cellular differentiation. Other normally present genes are those associated with neurodegenerative or congenital nervous system diseases, as well as genes thought to be mutated in several congenital CNS malformations (supplemental material, available at www.jneurosci.org).

\section{Day 1 postinjury: gene expression changes are related to tissue damage control}

Because we had observed that each K-means cluster had a unique molecular identity, we compared the overall functional characteristics of the bins displaying expression changes after contusion injury (i.e., $4+5,6+7,8,9$, and 10). In doing so, we first observed that injury to the spinal cord results in a major decline in neural gene expression from the 600 neural character transcripts observed in the normal spinal cord (Table 1, sum of Bins 1, $2+3$, and 10, neural-related genes) to 38 (Table 1 , Bins $4+5$, neural-related genes) at $1 \mathrm{~d}$ after injury. Persisting neural character genes include those coding for the NMDA receptor, glutamate transporter, and potassium ion channel and are accompanied by increased expression of transcripts for survival of motor neuron factor, GAP 43, neurorep-1, and collapsin-responsive mediator protein-3.

Concurrent with the loss of neural-related transcripts, increased gene expression at $1 \mathrm{~d}$ after injury (Bins $4+5$ ) is characterized by transcripts linked to hemostasis, hypoxia response, inflammation, and the initiation of the vascular and tissue repair process. These clusters are partnered with transcripts that participate in cellular damage control by protein salvage (i.e., HSP transcripts) and disposal (i.e., proteasomal transcripts) and DNA stabilization. Concomitantly, there is a substantial upregulation of growth-promoting transcripts preceding the increased cellular proliferation that occurs at day 3 postinjury (see next section).

To achieve hemostasis, multiple clotting-associated genes are expressed along with transcripts contributing to a fibronectinbased provisional matrix and $\beta$-integrin signaling. Concomitantly, genes encoding for angiogenic factors upregulate, including vascular endothelial growth factor (VEGF) and its receptor Flt-1. There is an accompanying increase in transcripts for enzymes that coordinate hypoxia response and growth modulator signaling with reactive oxygen species (ROS) production required for angiogenesis (Gordillo and Sen, 2003). In cooperation with these transcripts, immune-associated genes expressed at day 1 are proinflammatory and/or vasoactive mediators such as interleukins (IL)-1 and -6, CCL2 and CXCL1, macrophage inflammatory proteins $1 \mathrm{a}, 1 \mathrm{~b}$, and 2 , acute phase proteins, and kininogens.

Over 80 growth-related genes are found at day 1 (Table 1, supplemental material, available at www.jneurosci.org). These include the families of vascular endothelial, platelet-derived, fibroblast, insulin-like, and TGFs and their receptors. In addition, increased gene expression of growth regulating species such as retinoids, thyroid hormone, ornithine decarboxylase, and oncogene families such as Myc, Jun, and Fos was observed. These day 1 growth-promoting transcripts are initiators of cell-cycle activity and protein synthesis and are followed at day 3 by large increases in transcripts coding for cellular division and the translational apparatus (see next section and Table 1 , Bins $6+7$ ). This temporal juxtaposition of initiators with effectors is just one demonstration of many transcriptional interrelationships that were observed across all postinjury time intervals. process, it was placed in that specific category. Genes identified only by biochemical function were placed in the following biochemical support categories: cell cycle (pink), DNA-related (dark green), protein manufacture (fuschia), protein degradation (wine), protein trafficking (purple), heat shock proteins (deep orange with gray slash marks), oxidative metabolism (deep orange), lipid metabolism (orange), metabolism- glycolysis (light pink), metabolism - other (red), intracellular signaling (khaki), function unknown (black), and insufficient database (navy blue). For categories in which bars are cropped, the probe set count is 371 for bin $2+3$, neural-related and 104 for bin 9 , vascular repair. 
Table 1. Tabulation of K-means clustered probe sets by functional category and bin. Categories are color coded by function. Bins correspond to time postinjury. Counts of significantly expressed probe sets are listed after each category for each bin

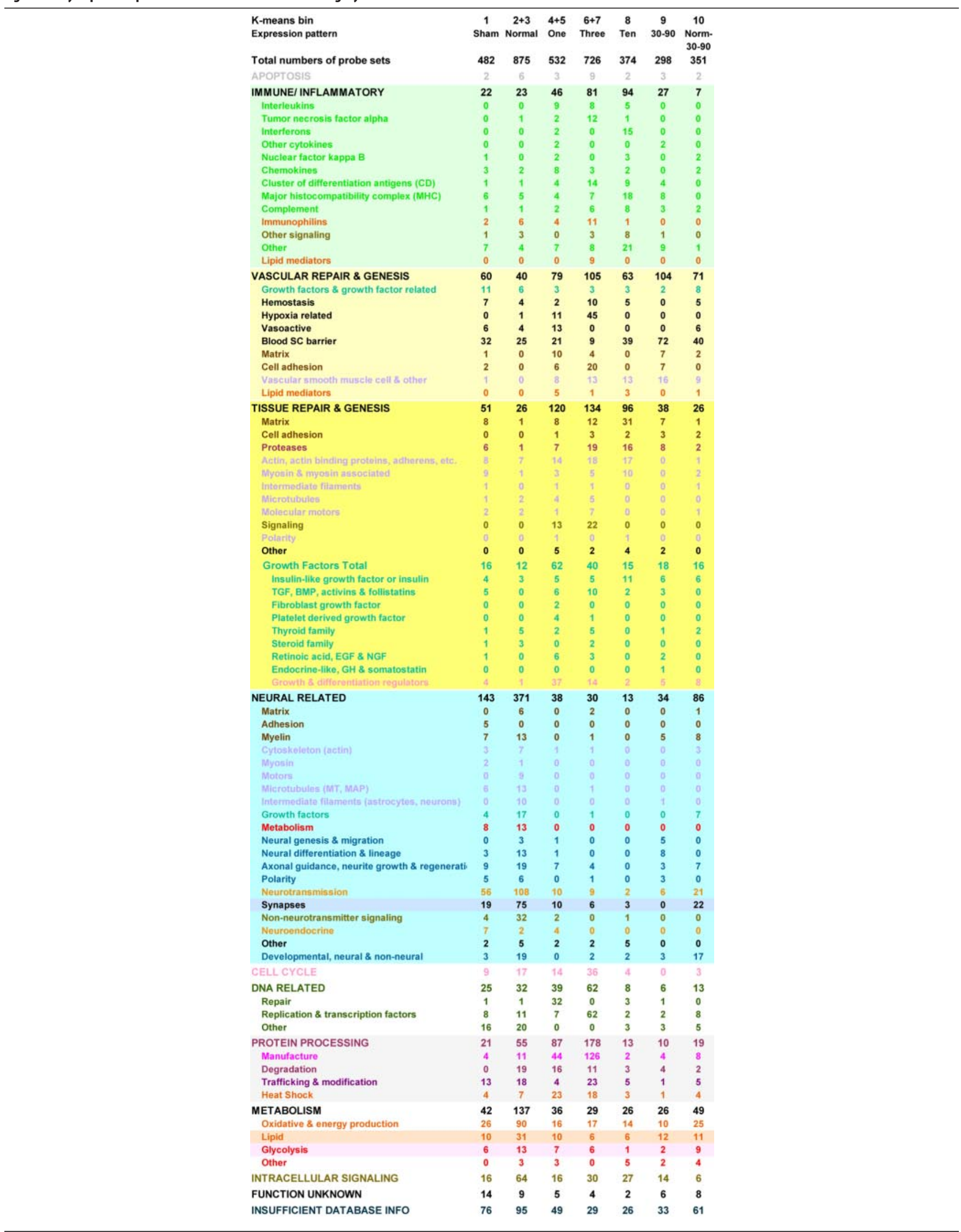


Repair and disposal of nucleic acids and damaged proteins are signified by the character of the transcript families upregulated at $24 \mathrm{hr}$ after injury. For example, the vast majority of the 39 DNArelated genes in this bin are those devoted to restoration of DNA integrity (e.g., nucleoporins and associated molecules, breast cancer associated-1, DNA polymerase $\epsilon$, excision repair, growth arrest, and DNA damage inducible proteins) and those that participate in the manufacture, breakdown, and degradation of nucleotide bases. The upregulation of the genes for 105, 70, 60, 40, and $10 \mathrm{kDa}$ HSPs, in addition to more specialized family members such as $\alpha$-crystallin, denotes an increase in protein chaperone activity. Removal of irreparably damaged proteins is indicated by the shift toward proteosomal protein and nonlysosomal degradation transcripts.

\section{Day 3 postinjury: hypoxia-induced shift in gene expression toward active cellular proliferation and mobilization for repair}

At day 3 after injury, the overall picture of gene expression changes dramatically from a damage-control transcriptional profile to one of active repair involving cellular proliferation and migration (Fig. 3, Table 1, supplemental material, available at www.jneurosci.org). DNA-related genes switch from a reparative to a replicative character. This occurs in coordination with the expression of cell cycle genes, oncogenes, and associated cytoskeletal and signaling transcripts. The most salient feature of this replication-oriented cluster is the simultaneous upregulation of 126 genes involved in the translational machinery and protein manufacture (Fig. 3B, Table 1), ranging from initiation and splicing factors to RNA helicases and the transcripts for all but two eukaryotic large ribosomal subunit genes.

Day 3 includes an interactive group of heme- and hypoxiaresponsive transcripts that comprise one of the larger cooperative gene clusters unveiled by our analysis. Free heme is known to be released by CNS trauma (Anderson and Means, 1985), and the entire cadre of transcripts that process heme for recycling increases in expression at this time. Heme processing, concomitant tissue hypoxia, and ROS production (Stone and Collins, 2002) are known activators of multiple transcript families that are increased at day 3 and regulate cell proliferation and migration, angiogenesis, metabolism, and apoptosis. One of these, hypoxia inducible factor-1 $\alpha$, along with a cluster of downstream genes, stimulates cell division in immune, mesenchymal, and vascular repair cells, populations previously shown to be immigrating at this postinjury interval (Goodman et al., 1979; Means and Anderson, 1983; Xu et al., 1990; Popovich et al., 1997; Taoka et al., 1997; Carlson et al., 1998; Chatzipanteli et al., 2000; Leskovar et al., 2000; Mautes et al., 2000; Casella et al., 2002; Loy et al., 2002; Noble et al., 2002) (P. R. Williams and M. J. Velardo, unpublished observations). In conjunction with these hypoxia-related transcripts, angiogenesis-initiating transcripts are the most abundant at this day of all postinjury intervals examined. They include prostaglandins, 5-lipoxygenase, phospholipase D, annexin family, platelet activating factor, platelet-endothelial cell adhesion molecule-1, neurotensin, urokinase PA, thrombospondin, and thromboplastin, in association with the growth factor and matrix proteins outlined below.

Hypoxia-induced proliferative events are supported by transcripts from multiple well established tissue repair and morphogenesis gene families that regulate growth and promote cytoskeletal rearrangement, diapedesis, and matrix remodeling. To that end, 59 cytoskeleton-associated transcripts (Table 1, supplemental material, available at www.jneurosci.org), including actin, ac- tin binding protein, myosin, molecular motor, microtubule and the associated ras, rab, and rho signaling protein families, are upregulated. The number of cell division modulators is second in magnitude only to day 1, encompassing 40 growth factors, stimulators, and/or cell cycle regulators (Table 1, supplemental material, available at www.jneurosci.org). The subset of growth factor gene families includes IGF, TGF $\beta$, activin, follistatin, thyroid, and steroid hormones and those that moderate downstream growth factor signaling. They actively modulate cellular proliferation and also ECM structural and proteolytic components that are abundant at day 3. In keeping with the proliferative nature of the genes at this time after injury, all these tissue repair transcripts have been demonstrated to coordinate with angiogenic matrix protein transcripts upregulated in this bin to assemble a granulation tissue matrix conducive to repair cell genesis, proliferation, and migration.

Also as a direct result of hypoxia and vascular transcript initiated events, the inflammatory transcriptional response is substantial at day 3 , being the second highest of all time points (Table 1, supplemental material, available at www.jneurosci.org). The cytokine profile is dominated by tumor necrosis factor (TNF) $\alpha$ related genes found in conjunction with IL-15 and -18, receptors for IL-1 and -4, chemokines C-X-C and CKR5, multiple clusters of differentiation antigens (CD), immunophilins, and many others. The presence of cells known to secrete or respond to TNF $\alpha$ can be inferred from the transcripts for cell surface markers in this bin that identify platelets and early pre-B cells (CD9), platelets, monocytes and macrophages (CD63), and early T and B cells (CD38).

\section{Day 10 postinjury: immune regulation of injury site remodeling and neovascularization}

The genes of day 10 fall almost entirely into immune or vascular and tissue repair-genesis categories (Fig. 3, Table 1, supplemental material, available at www.jneurosci.org). Upregulation of immune genes is the highest overall at this time postinjury ( 94 probe sets). As noted at days 1 and 3, the profile is dominated by a single regulatory cytokine family, in this case, interferon $\gamma$ (IFN $\gamma)$. The other significant immune gene families of this bin are the major histocompatibility complex (MHC), both class I and II (17 probe sets), a very large number of complement and related transcripts, and the immune CDs for activated T cells (SD only), B-lymphocytes, and dendritic cells. Both immune and other gene family members in this bin have been demonstrated to regulate these processes, suggesting a balance between proliferation and growth suppression, cell motility, and attachment, and proteolytic breakdown and rebuilding, all characteristics of tissue matrix remodeling and vascular repair.

These findings are in register with histological features seen at day 10 postinjury. At that time, the density of trafficked cells is more appreciable than at any of the other postlesion intervals studied and includes endothelial cells (ECs) and vascular smooth muscle cells (VSMCs) (data not shown). Transcripts involved in stimulating and regulating vascular repair and neogenesis are present, such as granulin (He et al., 2003), neuropilin ( $\mathrm{Gu}$ et al., 2003), and IGF family members (Smith et al., 1997), which figure prominently with nine probe sets. Furthermore, multiple motility, cytoskeletal, and polarity transcripts show increased expression. Simultaneously, there is upregulation of a subcluster of coagulation factors, lipid mediators (e.g., prostaglandin and thromboxane), structural genes for adherens junction formation (e.g., AIF-1 and occludins), and growth suppressive transcripts (e.g., B-cell translocation gene-1). This pattern, in 
conjunction with the limited number of nonreplicationrelated cell cycle and DNA-related genes and the maturation of blood vessels noted histologically, specifically signifies a slowing of vascular repair-related proliferation.

Gene families that enable wound contraction and matrix remodeling form a backdrop for the immune and vascular transcript activity described above. Actin transcription is required during this period of matrix remodeling for wound contraction via the classic purse string mechanism (Martin and Lewis, 1992). Collagen is the key matrix component indicated by 24 probe sets for types I, V, and XI and procollagen types I, III, V, XII, and XV and associated genes. Proteoglycan transcripts for known collagen cross-linking proteins are also present. The proteolytic aspect of remodeling is represented by a host of proteases that act on collagen or related matrix molecules.

\section{Days 30 through 90: two distinct K-means patterns reflect continuing tissue repair and partial restoration of preinjury neural transcript expression}

In contrast with earlier postcontusion intervals, we identified at least two distinct K-means expression profiles for the 30-90 d postinjury interval. These patterns reflect two different functional states of the molecular repair process after spinal injury. Overall, the genes in the first K-means cluster that describes this time period (Bin 9) signify de novo repair-directed transcript expression (i.e., matrix and blood vessel remodeling with a strong focus on vascular maturation) during the chronic injury phase. The second pattern of transcript expression (Bin 10) suggests partial reacquisition of the normal character of the SC, that is, some transcripts that were highly expressed in noncontused SCs showed decreased expression immediately after injury but then returned to high expression levels in animals at longer postinjury time intervals.

\section{Tissue remodeling and reestablishment of the blood-SC barrier}

The gene families expressed uniquely at days 30-90 postinjury (Bin 9) are devoted to the regulation of neovascularization, the concomitant differentiation of ECs and VSMCs, and formation of the tight junctions characteristic of maturing vasculature. These include matrix, peroxisome proliferator, growth factor, and oxyradical-related genes. The ECM-related transcripts include multiple serine proteases and tissue matrix structural components, as well as vascular cell adhesion molecule-1, integrin $\beta-4$, heparin sulfate proteoglycan core protein, glypican-3, tenascin-X, vitronectin, F-spondin, and SPARC (secreted protein acidic rich in cysteine), all of which have been identified as having well defined roles in remodeling and angiogenesis. Furthermore, several of these matrix molecules, along with four transcripts for peroxisome proliferators, are newly recognized key regulators of angiogenesis and tumor suppression (Xin et al., 1999; Terai et al., 2001; Sage et al., 2003; Zhou et al., 2003).

Accordingly, other transcripts found in this cluster, such as angiopoietin and pleiotrophin, promote EC differentiation and inhibit angiogenesis, respectively. Increased expression likewise occurs among IGF family transcripts, which play a role in neovascularization, and latent transforming growth factor binding protein, which regulates TGF $\beta$ activity and targets it to VSMCs (Abe et al., 2002). Upregulation of genes encoding bone morphogenetic proteins (BMP)-4 and -6 also was detected. These two unusual TGF $\beta$ family members regulate neovascularization: BMP-4 directs capillary regression (Kiyono and Shibuya, 2003), and BMP-6 is highly expressed in ECs and VSMCs (Glienke et al., 2000).
From the transcript patterns, it is apparent that growth factorinduced maturation of the vascular bed via formation of tight junctions is tightly associated with transcripts participating in the repair and reestablishment of the blood-SC barrier. Recent studies have demonstrated that ROS drive both these processes (Gordillo and Sen, 2003). Members of the enzyme gene families that generate and control ROS are present, namely, catalase, glutathione peroxidase, and glutathione $S$-transferase, plus the transcripts for the accompanying requisite metabolism of selenium. VSMC maturation is signified by transcripts for calponin III and smooth muscle myosin, zona occludens proteins- 1 and -2, apolipoprotein E, and other lipid-regulating molecules that imply EC differentiation. Transcripts such as PAR-6 (partitioning defective protein-6), Wnt 5a, and frizzled homolog furnish polarity cues for this process. Their presence, in conjunction with multiple transporter, multidrug resistance, and cytochrome P450 genes (de Boer et al., 2003), indicates that in tandem with EC maturation, blood-SC barrier integrity and function is being reestablished. The expression and timing of these transcript clusters in association with the transcript expression and immunostaining patterns for glutathione $S$-transferase, a known blood-SC barrier marker, strongly support the coordination of these two processes (see immunohistochemistry results described below and Fig. $4 E$ ).

At days 30-90, immune involvement, as suggested by overall transcript numbers, is clearly waning. However, those immune genes that are present also function in vascular remodeling or the dampening of the immune response. Neural genes represent mostly transcription factors and developmental genes with some myelin- and neurotransmission-related transcripts. There is a total absence of any synaptic function transcripts and an increase in glial fibrillary acidic protein, which would correspond with blood-SC barrier reconstruction and possibly some astrocytic hypertrophy at this 30-90 d interval.

\section{Days 30-90: partial return of normal transcript expression at the lesion epicenter}

As described above, Bin 9 genes are increased as a result of de novo processes. In contrast, the Bin $10 \mathrm{~K}$-means profile describes transcripts that are highly expressed in noncontused SC, decrease in expression immediately after injury, and slowly return to having increased expression at later times. Accordingly, the Bin 10 neural gene profile has a more normal appearance with predicted transcripts such as neurotransmitters, receptors, and synthesizing enzymes along with those related to synapses. Also, as observed in the noncontused SC profile, there are a large number of vasculature-related growth and tumor suppressor genes. Some transcript families thought to be associated with neurodegeneration (e.g., $\alpha$ and $\gamma$ synucleins, prion protein, amyloid precursor protein binding protein-1, and neurodegeneration-associated protein-1) are also expressed in normal SC and upregulate again at 30-90 d postinjury. Metabolic support transcripts increase in expression compared with previous injury bins, especially in terms of mitochondrial energy production, glycolysis, and lactate metabolism, but are not as robustly expressed as in normal spinal cord.

\section{Immune response, tissue, and vascular repair genes predominate in the postcontusion transcriptional profile} The detailed analysis of all transcripts allowed us to assign unique functional molecular signatures to each postlesion time interval studied. We then asked whether there was a discernible global pattern to the injury response. The analyzed expression map has been presented in a format that is color-coded by function in the 


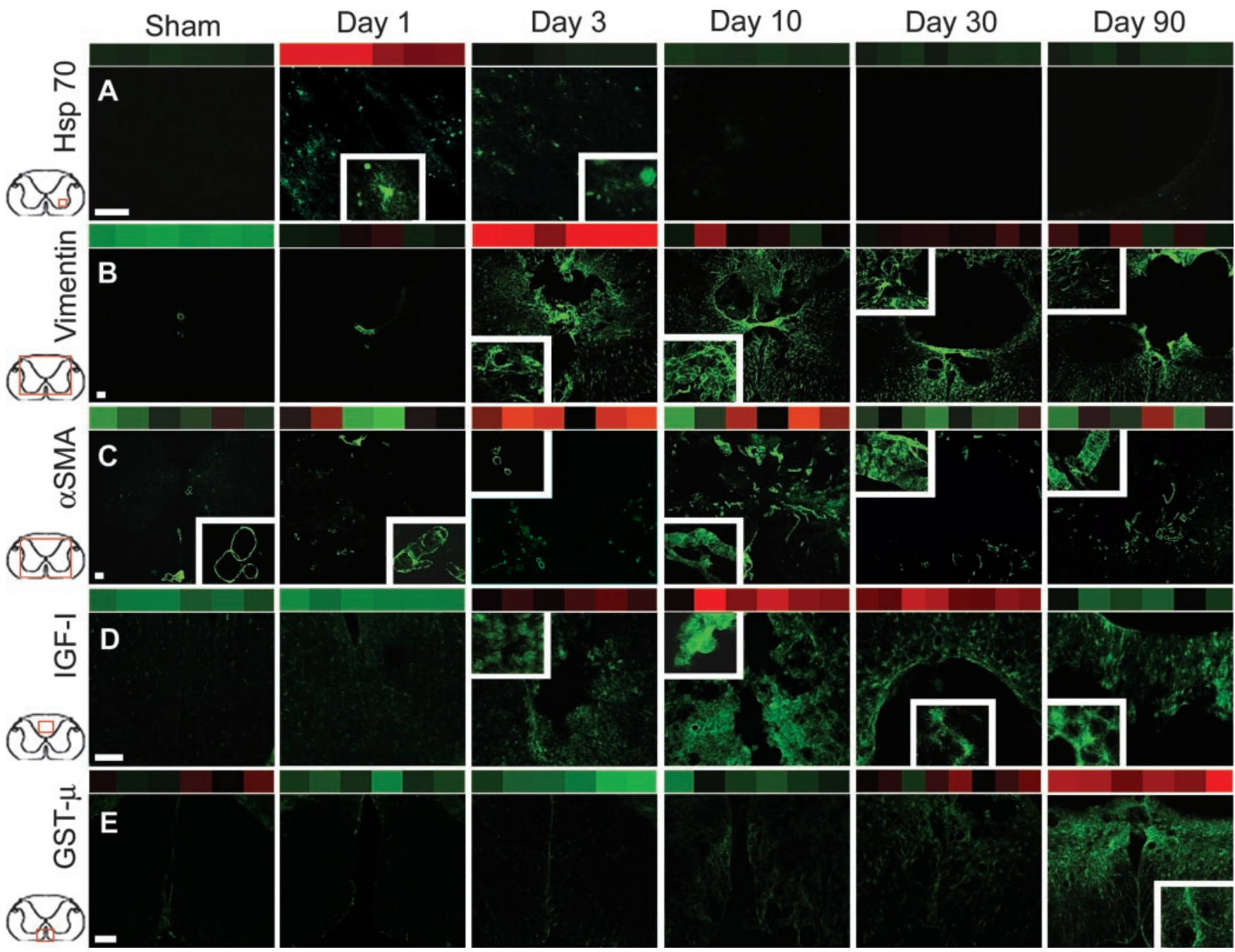

Figure 4. Protein expression, as determined by immunofluorescent histochemistry, corresponds with array expression profiles for genes representative of important biological processes occurring at each postinjury time point $(A-E)$. Array results (indicated by colored insets across the top of each photomicrograph) are shown for both strains, because genes were selected that did not display strain differences by either microarray analysis or immunostaining. Therefore, sections from a single strain are shown per antibody. Low-power photomicrographs show relative expression and are from the areas outlined in red boxes on the spinal cord diagrams. Higher-power insets illustrate cellular morphology and distribution. (Gene names, accession numbers, and rat strain are in parentheses; scale bars, $100 \mu \mathrm{m}$ ). In A, at day 1: anti-HSP 72/73 IR is found primarily in ventral horn, intermediate gray, and ventromedial aspect of dorsal horn and tapers off by day 3 (HSP70, Z27118, L16764; AN rat). In B, at day 3: vimentin-IR is located in ependyma and cells with astrocyte-like morphology in white and gray matter with the exception of dorsal horn (vimentin, X62952; $S D$ rat). In C, at day 10: anti-smooth muscle actin IR is evenly distributed in large-caliber vascular structures throughout the section and greatly increased in small-and medium-caliber vessels at this time point (vascular $\alpha$ actin, smooth muscle, X06801; SD rat). In D, at days 10 and 30: anti-IGF-1 immunostaining occurs most prominently in dorsal columns (insulin-like growth factor-1, X06107, M81183, M15481, D00698; AN rat). In E, at day 90: anti-glutathione $S$-transferase, $\mu$ type immunostaining shown in ventromedial white matter. Inset depicts putative astrocytes surrounding blood vessel (glutathione S-transferase, $\mu$ type, H32189, X04229, J02592, J03914, E01415, J02810, U86635; SD rat).

supplemental material (available at www.jneurosci.org), and reveals that overall transcript expression after injury is dominated by immune response and tissue-vascular repair and genesis gene families (supplemental material, available at www.jneurosci.org) that are functionally interrelated. The postinjury immune response is comprised of at least 255 probe sets (Table 1, light green background, supplemental material, available at www.jneurosci.org), and vascular repair and genesis gene families are represented by 422 probe sets (Table 1, pale yellow background, supplemental material, available at www.jneurosci.org). Of the tissue repair and genesis category (414 probe sets) (Table 1, dark yellow background, supplemental material, available at www.jneurosci.org), two key groups are comprised of those transcripts for growth regulation and matrix construction-remodeling. In addition, the majority of remaining postinjury transcripts that do not directly belong to these families code for proteins that provide replica- tion, metabolic, cellular signaling, and other biochemical support for these immune or repair-related functions (Table 1, supplemental material, available at www.jneurosci.org).

\section{Immunostaining for representative genes corresponds with} microarray expression patterns

To determine whether there is a meaningful relationship between transcript expression, as shown by the microarray data and expression of the proteins in the injury environment, we performed immunohistochemistry on tissue sections (Fig. 4). The representative genes were selected by several criteria: (1) the genes were typical of biological processes occurring at that time point, (2) both the genes and their immunohistochemical staining patterns were well characterized, and (3) there were no detectable strain differences in gene expression. The selected proteins included: (1) the chaperonin HSP-70 to represent the protein rescue func- 
tions of day 1, (2) the intermediate filament vimentin for its function in proliferation, the hallmark of day 3, (3) $\alpha$ smooth muscle actin ( $\alpha \mathrm{SMA})$ for its role in neovascularization, a day 10 function, (4) IGF-1 to represent day 30, because of its upregulation and participation in the remodeling and angiogenesis functions of days 10 and 30 and the prominent role of its family members in $\mathrm{WH}$, and (5) glutathione $S$-transferase, $\mu$ subtype $(\mathrm{GST}-\mu)$ to represent day 90 , because of its strong expression and role in reestablishment of the blood-SC barrier (de Boer et al., 2003).

HSP 70 (anti-HSP72/73) is upregulated only at day 1 on the array, and the same is true for its immunoreactivity (IR), which is mostly neuronal (Fig. 4A). Gene expression for vimentin increases sharply at day 3. Vimentin IR is present only in the ependymal cells of normal animals, and this ependymal staining increases at days 1 and 3. By day 3, vimentin IR appears in cells with astrocytic morphology along blood vessels and scattered throughout the surviving white and gray matter, except for the dorsal horn. As might be expected because of its structural nature, vimentin IR persists in filaments of the astrocyte-like cells from 10 to $90 \mathrm{~d}$ but gradually decreases over that time until ultimately by $90 \mathrm{~d}$, it is found primarily in those cells that line the contusion cysts formed after the contusion (Fig. $4 B$ ).

Actin-related transcripts of all types are prominent at days 3 and 10. In normal, sham, and injured animals, $\alpha$ SMA-IR was present in large-caliber vascular structures such as the ventral spinal artery and vein. At day 3, it appeared in small caliber intraparenchymal vessels, and by day 10 , the staining intensified dramatically (Fig. 4C) in vessels of all calibers. Although the staining persisted to $90 \mathrm{~d}$, it decreased in intensity after day 10 and localized to large vessels lining the cysts. In normal and sham spinal cords, extremely low-level IGF-1 IR is present in the neuropil and scattered neural cell bodies. After injury, IGF-1 IR appears at day 10 in immune cells at the lesion epicenter and also in white-matter cells with glial-like morphology (Fig. 4D). In register with the array pattern, the strong immune cell-related staining tapers off over time after day 10, whereas the weaker glial-like staining becomes more prevalent in white matter. As in the other cases, the immunostaining for GST- $\mu$ was very weak to nonexistent in the normal, sham, and earlier postinjury animals. However, at day 90, cell body immunostaining was detected in nonneuronal elements that exhibited a glial-like morphology (Fig. $4 E)$. Although it was distributed throughout white matter, it was most intense in both dorsomedial and ventromedial regions and the dorsal columns immediately rostral to the epicenter.

\section{Discussion \\ Functional analysis of the post-SCI transcriptional profile reveals a striking resemblance to dermal wound healing}

By using a high-density microarray platform in conjunction with a mechanism-based analytical strategy, we generated a temporal representation of the functional interrelationships found within the transcriptional response to cervical SCI. The pattern of transcript expression was highly orchestrated from 1 to $90 \mathrm{~d}$ after injury and consistent in two distinct rat strains. As seen with thoracic contusions (Carmel et al., 2001; Song et al., 2001; Nesic et al., 2002; Tachibana et al., 2002; Di Giovanni et al., 2003; Pan et al., 2004), a profound loss of neural gene expression was observed by $1 \mathrm{~d}$ post-SCI. In our longitudinal study, a very modest rebound occurred by $90 \mathrm{~d}$ postinjury, reflective of neural tissue loss within the lesion. Furthermore, our results demonstrate that this rapid decline in expression of neural-specific transcripts was accompanied by significantly increased representation of tissue repair genes that are remarkably similar to those acting in dermal $\mathrm{WH}$. Even more compelling is the resemblance of the timing and sequence of post-SCI gene expression to the well established serial, but overlapping, stages of cutaneous WH (Clark, 1993; Martin, 1997; Witte and Barbul, 1997; Singer and Clark, 1999). These include: (1) hemostasis via vasoconstriction, platelet aggregation, and clot formation (1-3 d), (2) immune response (1-21 d), (3) cellular proliferation-migration accompanied by granulation tissue formation, angiogenesis, and wound contraction (3-30 d), and (4) a long remodeling phase (10 d to 24 months) underlying the preceding processes (supplemental material, available at www.jneurosci.org).

In skin, the WH process is controlled by interactions of immune, hematogenous, and tissue repair cellular populations trafficking in and out of the injury site at specific times. SC anatomy (i.e., with vascular, perivascular, dural, and pial compartments) dictates that SCI would entail a complex postinjury vascular and inflammatory cellular response. Our SCI-WH hypothesis is viable because histological studies have clearly demonstrated that these cell types participate in the postcontusion process (supplemental material, available at www.jneurosci.org) (Goodman et al., 1979; Means and Anderson, 1983; Xu et al., 1990; Popovich et al., 1997; Taoka et al., 1997; Carlson et al., 1998; Chatzipanteli et al., 2000; Leskovar et al., 2000; Mautes et al., 2000; Casella et al., 2002; Loy et al., 2002; Noble et al., 2002) (Williams and Velardo, unpublished observations). In our model, we show that many WH-related cellular populations are present at the appropriate times after contusion, with the exception of fibroblasts (supplemental material, available at www.jneurosci.org). Therefore, SCI is not confined to neurons and glia, and future in situ hybridization or immunohistochemical analyses will be required to ascribe identified transcript functions to specific cellular populations.

As with skin $\mathrm{WH}$, the orchestrated expression of immune transcripts at $1,3,10$, and $30 \mathrm{~d}$ postinjury appears to play a pivotal role in SCI over long postinjury intervals (supplemental material, available at www.jneurosci.org). Other SCI microarray (Carmel et al., 2001; Song et al., 2001; Tachibana et al., 2002; Pan et al., 2004) and directed studies (Popovich et al., 1996; Huang et al., 1999; Bethea, 2000; Bethea and Dietrich, 2002; Jones et al., 2002; Pan et al., 2002; Schwartz and Hauben, 2002; Hausmann, 2003) have shown that inflammation plays a major role in acute SCI. Our dataset further demonstrates the apparent regulatory roles of major cytokine families, the extensive orchestration of the immune response, its interrelationship with repair gene families, and a previously unreported persistence of this response in the subacute and chronic stages of SCI (Table 1, supplemental material, available at www.jneurosci.org).

The key initiator of immune cascades, IL-1, increases early after injury (Wang et al., 1997; Carmel et al., 2001; Pan et al., 2002), and members of this family persist strongly at day 1 in our dataset (supplemental material, available at www.jneurosci.org). Both IL- 1 and TNF $\alpha$ (supplemental material, available at www. jneurosci.org) are proinflammatory cytokines that induce expression of provisional matrix (supplemental material, available at www.jneurosci.org) and granulation tissue components (supplemental material, available at www.jneurosci.org). They regulate the innate immune response of macrophages and initiate WH growth factor production (Henry and Garner, 2003; Werner and Grose, 2003). TNF $\alpha$ family immune genes are prominent at day 3 and have multifunctional relationships with hypoxiainitiated transcription (Harris, 2002), vascular repair, cellular proliferation and death, and priming of immune and WH cells for the actions of IFN $\gamma$ (Battegay et al., 1995; Venters et al., 2000; 
Brunel and Chandel, 2002; Hallenbeck, 2002; Zhou et al., 2003). These related processes have strong transcript representation at day 3 (supplemental material, available at www.jneurosci.org). At $10 \mathrm{~d}$ postinjury, the IFN $\gamma$ family predominates (supplemental material, available at www.jneurosci.org). It is known to regulate WH via crosstalk with TGF $\beta$ signaling (Ishida et al., 2004) (supplemental material, available at www.jneurosci.org), along with suppression of granulation tissue and regulation of collagen production (Higashi et al., 2003) (supplemental material, available at www.jneurosci.org). This family also controls the activation of the macrophage phenotype (Moser, 2002) (supplemental material, available at www.jneurosci.org), inhibits angiogenesis (Strieter et al., 1995), plays a role in neointimal formation (Zohlnhofer et al., 2001), and alters tight junctions (Walsh et al., 2000) (supplemental material, available at www.jneurosci.org).

In coordination with the inflammatory response, other early post-SCI transcriptional patterns indicate that injury site hypoxia induced by vascular damage and coagulation drives angiogenesis, neovascularization, and cellular proliferation-related transcript expression (supplemental material, available at www.jneurosci.org) in a manner similar to that of WH (Tonnesen et al., 2000). From our analysis, it was evident that as in $\mathrm{WH}$, vascular repair-genesis plays an essential role in the post-SCI transcriptional profile (supplemental material, available at www.jneurosci.org). This assertion is supported by previous SCI (Mautes et al., 2000; Casella et al., 2002; Loy et al., 2002; Noble et al., 2002) and MRI studies (Bilgen et al., 2001).

Growth factors characterized by TGF, FGF, VEGF, and IGF-1 gene families have integral functions in dermal WH (Werner and Grose, 2003). In support of our SCI-WH model, these same families are strongly represented at 1-3 d postinjury, whereas TGF and IGF-1 families are prominent from 1-90 d (supplemental material, available at www.jneurosci.org). TGF gene family predominance is significant because all cells involved in dermal wound repair can produce or respond to TGF isoforms, most of which are context and concentration dependent (O'Kane and Ferguson, 1997). Furthermore, in addition to well established astrocytic responses to TGF $\beta$ family (McKeon et al., 1999; Lagord et al., 2002; Silver and Miller, 2004), more recent evidence suggests novel roles for the TGF $\beta$ pathway in neuronal signaling and plasticity (Sanyal et al., 2004). The strong presence of these WHbased growth factor transcripts has significant implications pertaining to regeneration and self-repair mechanisms.

In cutaneous $\mathrm{WH}$, the ECM is dynamic and responsive to growth and other environmental factors (Stamenkovic, 2003). The postinjury ECM acts as a repair scaffold for cells and neovascular structures, as well as an instructive growth factor grid for cellular trafficking (Badylak, 2002). Our documentation of the molecular details of the postinjury transformation of the ECM is particularly relevant to SCI because of the large body of work proposing that regeneration is inhibited by certain matrix molecules and glial scarring (Grimpe and Silver, 2002; Morgenstern et al., 2002; Silver and Miller, 2004). One of the most striking similarities between SCI postinjury gene expression and dermal WH is the steady progression of transcript expression changes indicating a shift from a fibronectin- to a collagen-based matrix (supplemental material, available at www.jneurosci.org) (Eckes et al., 1996; Witte and Barbul, 1997). Collagen deposition is a key event in healing skin, synchronized with other matrix alterations, and a major factor in scarring. Collagen has frequently been dismissed as an impediment to SC regeneration because it is lost in processing injured tissue (Hermanns et al., 2001). Our findings suggest that perhaps this question deserves reconsideration. Similarly, comparisons between our results and ECM profiles associated with dermal scarring and inadequate WH (Steed, 2003) may provide insight into the timing and coordination of SC matrix restructuring and its effects on scarring, regeneration, and functional outcomes.

\section{Postinjury gene expression changes are highly conserved in two genetically and immunologically distinct rat strains}

The basic WH-SCI signature demonstrated in SD and AN strains differed by only 80 genes, emphasizing the robust nature and importance of this response. Nonetheless, varying SCI outcomes have been identified in diverse rat strains with comparable contusion injuries (Mills et al., 2001; Webb et al., 2003a), and postinjury recovery differed in the AN animals (data not shown). So, although the strain similarities are remarkable and support our WH hypothesis, because WH exhibits nonlinear dynamics in mathematical modeling terms (Sherrat and Dallon, 2002), it is also true that disparities in relatively small numbers of genes may have wide-ranging, significant effects.

\section{Relevance to the biology of SCI and its repair}

The parallel between the postinjury gene expression profile and dermal WH described here has multiple implications because it involves two tissues having common embryonic ectodermal origin. Critical to inferences associated with our SCI-WH hypothesis is the fact that WH mechanisms are tissue specific, differing in skin, liver, kidney, heart, lung, muscle, bone, mucosa, etc. (Clark, 1991; Strutz and Neilson, 2003; Szpaderska et al., 2003). Of considerable significance to CNS injury, wound repair results in true regeneration only in some tissues (e.g., liver, bone) (Michalopoulos and DeFrances, 1997; Tanaka, 2003; Poynton and Lane, 2004) and scarring or nonregenerative healing in others (e.g., adult skin, kidney, CNS) (Steed, 2003; Strutz and Neilson, 2003; Silver and Miller, 2004). Therefore, the resemblance of the post-SCI transcriptional profile to dermal $\mathrm{WH}$, which is of the scarring, nonregenerative type in adults, not only provides a conceptual framework for study of the underlying pathophysiology and repair mechanisms, but may also provide insights into the lack of regeneration that occurs after SCI (Goss, 1992; Tanaka, 2003).

Furthermore, these results suggest that intrinsic repair of the spinal cord exhibits "dynamic reciprocity," a characteristic of dermal WH described by Clark (1996) as "a complex interaction and feedback control of cells, cytokines, enzymes, matrix" and other molecules. It follows that a systems-based view of SCI is likely to foster success in terms of experimentation and therapies. For example, our microarray results, in conjunction with previous SCI histological findings, detail the changing microenvironment or niches of the post injury SC. The characteristics of that dynamic environment may contribute to our understanding of the absence of postinjury neurogenesis and the specific cellular phenotypes that arise after intraspinal stem cell transplantation. In addition, amalgamation of our findings with previously identified molecular participants in SCI, either neural-specific (e.g., Nogo) or more widely occurring (e.g., rho, ECM molecules), may lead to a clearer understanding of their inhibitory, neuroprotective, or regenerative molecular mechanisms (McKerracher and Winton, 2002).

\section{References}

Abe M, Oda N, Sato Y, Shibata K, Yamasaki M (2002) Augmented binding and activation of latent transforming growth factor-beta by a tryptic fragment of latency associated peptide. Endothelium 9:25-36.

Anderson DK, Means ED (1985) Iron-induced lipid peroxidation in spinal 
cord: protection with mannitol and methylprednisolone. J Free Radic Biol Med 1:59-64.

Badylak SF (2002) The extracellular matrix as a scaffold for tissue reconstruction. Semin Cell Dev Biol 13:377-383.

Bareyre FM, Schwab ME (2003) Inflammation, degeneration and regeneration in the injured spinal cord: insights from DNA microarrays. Trends Neurosci 26:555-563.

Battegay EJ, Raines EW, Colbert T, Ross R (1995) TNF-alpha stimulation of fibroblast proliferation. Dependence on platelet derived growth factor (PDGF) secretion and alteration of PDGF receptor expression. J Immunol 154:6040-6047.

Bethea JR (2000) Spinal cord injury-induced inflammation: a dual-edged sword. Prog Brain Res 128:33-42.

Bethea JR, Dietrich WD (2002) Targeting the host inflammatory response in traumatic spinal cord injury. Curr Opin Neurol 15:355-360.

Bilgen M, Abbe R, Narayan PA (2001) Dynamic contrast-enhanced MRI of experimental spinal cord injury: in vivo serial studies. Magn Reson Imaging 45:614-622.

Bradbury EJ, Moon LD, Popat RJ, King VR, Bennett GS, Patel PN, Fawcett JW, McMahon SB (2002) Chondroitinase ABC promotes functional recovery after spinal cord injury. Nature 416:636-640.

Brunel JK, Chandel NS (2002) Oxygen deprivation induced cell death: an update. Apoptosis 7:475-482.

Carlson SL, Parrish ME, Springer JE, Doty K, Dossett L (1998) Acute inflammatory response in spinal cord following impact injury. Exp Neurol 151:77-88.

Carmel JB, Galante A, Soteropoulos P, Tolias P, Recce M, Young W, Hart RP (2001) Gene expression profiling of acute spinal cord injury reveals spreading inflammatory signals and neuron loss. Physiol Genomics 7:201-213.

Casella GT, Marcillo A, Bunge MB, Wood PM (2002) New vascular tissue rapidly replaces neural parenchyma and vessels destroyed by a contusion injury to the rat spinal cord. Exp Neurol 173:63-76.

Chatzipanteli K, Yanagawa Y, Marcillo AE, Kraydieh S, Yezierski RP, Dietrich WD (2000) Posttraumatic hypothermia reduces polymorphonuclear leukocyte accumulation following spinal cord injury in rats. J Neurotrauma 17:321-332.

Clark RA (1991) The commonality of cutaneous wound repair and lung injury. Chest 99 [Suppl 3]:57S-60S.

Clark RA (1993) Biology of dermal wound repair. Dermatol Clin 11:647-666.

Clark RAF (1996) Wound repair: overview and general considerations. In: Molecular and cellular biology of wound repair (Clark RAF, ed), pp 3-35. New York: Kluwer-Plenum.

de Boer AG, van der Sandt ICJ, Gaillard PJ (2003) The role of drug transporters at the blood-brain barrier. Annu Rev Pharmacol Toxicol 43:629-656.

Di Giovanni S, Knoblach SM, Brandoli C, Aden SA, Hoffman EP, Faden AI (2003) Gene profiling in spinal cord injury shows role of cell cycle in neuronal death. Ann Neurol 53:454-468.

Does MD, Snyder RE (1996) Multiexponential T2 relaxation in degenerating peripheral nerve. Magn Reson Med 35:207-213.

Eckes B, Aumailley M, Kreig T (1996) Collagens and the reestablishment of dermal integrity. In: Molecular and cellular biology of wound repair (Clark RAF, ed), pp 493-512. New York: Kluwer-Plenum.

Eisen MB, Spellman PT, Brown PO, Bostein D (1998) Cluster analysis and display of genome-wide expression patterns. Proc Natl Acad Sci USA 95:14863-14868.

el-Bohy AA, Schrimsher GW, Reier PJ, Goshgarian HG (1998) Quantitative assessment of respiratory function following contusion injury of the cervical spinal cord. Exp Neurol 150:143-152.

Fawcett JW, Asher RA (1999) The glial scar and central nervous system repair. Brain Res Bull 49:377-391.

Fitch MT, Doller C, Combs CK, Landreth GE, Silver J (1999) Cellular and molecular mechanisms of glial scarring and progressive cavitation: in vivo and in vitro analysis of inflammation-induced secondary injury after CNS trauma. J Neurosci 19:8182-8198.

Glienke J, Schmitt AO, Pilarsky C, Hinzmann B, Weiss B, Rosenthal A, Thierauch KH (2000) Differential gene expression by endothelial cells in distinct angiogenic states. Eur J Biochem 267:2820-2830.

Goodman JH, Bingham Jr WG, Hunt WE (1979) Platelet aggregation in experimental spinal cord injury: ultrastructural observations. Arch Neurol 36:197-201.

Gordillo GM, Sen CK (2003) Revisiting the essential role of oxygen in wound healing. Am J Surg 186:259-263.

Goss RJ (1992) The evolution of regeneration: adaptive or inherent? J Theor Biol 159:241-260.

Grimpe B, Silver J (2002) The extracellular matrix in axon regeneration. Prog Brain Res 137:333-349.

Gu C, Rodriguez ER, Reimert DV, Shu T, Fritzsch B, Richards LJ, Kolodkin AL, Ginty DD (2003) Neuropilin-1 conveys semaphorin and VEGF signaling during neural and cardiovascular development. Dev Cell 5:45-57.

Hackney DB, Asato R, Joseph PM, Carvlin MJ, McGrath TJ, Grossman RI, Kassab EA, DeSimone D (1986) Hemorrhage and edema in acute spinal cord compression: demonstration by MR imaging. Radiology 161:387-390.

Hallenbeck JM (2002) The many faces of tumor necrosis factor in stroke. Nat Med 8:1363-1368.

Harris AL (2002) Hypoxia-a key regulatory factor in tumour growth. Nat Rev Cancer 2:38-47.

Hausmann ON (2003) Post-traumatic inflammation following spinal cord injury. Spinal Cord 41:369-378.

He Z, Ong CH, Halper J, Batemanm A (2003) Progranulin is a mediator of the wound response. Nat Med 9:225-229.

Henry G, Garner WL (2003) Inflammatory mediators in wound healing. Surg Clin North Am 83:483-507.

Hermanns S, Klapka N, Muller HW (2001) The collagenous lesion scar-an obstacle for axonal regeneration in brain and spinal cord injury. Restor Neurol Neurosci 19:139-148.

Higashi K, Inagaki Y, Fujimori K, Nakao A, Kaneko H, Nakatsuka I (2003) Interferon- $\gamma$ interferes with transforming growth factor- $\beta$ signaling through direct interaction of YB-1 with Smad3. J Biol Chem 278:43470-43479.

Hill CE, Beattie MS, Bresnahan JC (2003) The interplay of secondary degeneration and self-repair after spinal cord injury. Top Spinal Cord Inj Rehabil 8:1-13.

Huang DW, McKerracher L, Braun PE, David S (1999) A therapeutic vaccine approach to stimulate axon regeneration in the adult mammalian spinal cord. Neuron 24:639-647.

Hulsebosch CE (2002) Recent advances in pathophysiology and treatment of spinal cord injury. Adv Physiol Educ 26:238-255.

Inman D, Guth L, Steward O (2002) Genetic influences on secondary degeneration and wound healing following spinal cord injury in various strains of mice. J Comp Neurol 451:225-235.

Ishida Y, Kondo T, Takayasu T, Iwakura Y, Mukaida N (2004) The essential involvement of cross-talk between IFN-gamma and TGF-beta in the skin wound healing process. J Immunol 172:1848-1855.

Jones TB, Basso DM, Sodhi A, Pan JZ, Hart RP, MacCallum RC, Lee S, Whitacre CC, Popovich PG (2002) Pathological CNS autoimmune disease triggered by traumatic spinal cord injury: implications for autoimmune vaccine therapy. J Neurosci 22:2690-2700.

Jones TB, Ankeny DP, Guan Z, McGaughy V, Fisher LC, Basso DM, Popovich PG (2004) Passive or active immunization with myelin basic protein impairs neurological function and exacerbates neuropathology after spinal cord injury in rats. J Neurosci 14:3752-3761.

Kipnis J, Mizrahi T, Hauben E, Shaked I, Shevach E, Schwartz M (2002) Neuroprotective autoimmunity: naturally occurring CD4+CD25+ regulatory $\mathrm{T}$ cells suppress the ability to withstand injury to the central nervous system. Proc Natl Acad Sci USA 99:15620-15625.

Kiyono M, Shibuya M (2003) Bone morphogenetic protein 4 mediates apoptosis of capillary endothelial cells during rat pupillary membrane regression. Mol Cell Biol 23:4627-4636.

Kleitman N (2004) Keeping promises: translating basic research into new spinal cord injury therapies. J Spinal Cord Med, in press.

Koshinaga M, Sanon HR, Whittemore SR (1993) Altered acidic and basic fibroblast growth factor expression following spinal cord injury. Exp Neurol 120:32-48.

Lagord C, Berry M, Logan A (2002) Expression of TGFbeta2 but not TGFbetal correlates with the deposition of scar tissue in the lesioned spinal cord. Mol Cell Neurosci 20:69-92.

Lemons ML, Sandy JD, Anderson DK, Howland DR (2001) Intact aggrecan and fragments generated by both aggrecanase and metalloproteinase-like 
activities are present in the developing and adult rat spinal cord and their relative abundance is altered by injury. J Neurosci 21:4772-4781.

Leskovar A, Moriarty LJ, Turek JJ, Schoenlein IA, Borgens RB (2000) The macrophage in acute neural injury: changes in cell numbers over time and levels of cytokine production in mammalian central and peripheral nervous systems. J Exp Biol 203:1783-1795.

Logan A, Berry M (1993) Transforming growth factor-beta 1 and basic fibroblast growth factor in the injured CNS. Trends Pharmacol Sci 14:337-342.

Loy DN, Crawford CH, Darnall JB, Burke DA, Onifer SM, Whittemore SR (2002) Temporal progression of angiogenesis and basal lamina deposition after contusive spinal cord injury in the adult rat. J Comp Neurol 445:308-324.

Martin P (1997) Wound healing-aiming for perfect skin regeneration. Science 276:75-81.

Martin P, Lewis J (1992) Actin cables and epidermal movement in embryonic wound healing. Nature 360:179-183.

Mautes AE, Weinzierl MR, Donovan F, Noble LJ (2000) Vascular events after spinal cord injury: contribution to secondary pathogenesis. Phys Ther 80:673-687.

McKeon RJ, Jurynec MJ, Buck CR (1999) The chondroitin sulfate proteoglycans neurocan and phosphacan are expressed by reactive astrocytes in the chronic CNS glial scar. J Neurosci 19:10778-10788.

McKerracher L, Winton MJ (2002) Nogo on the go. Neuron 36:345-348.

Means ED, Anderson DK (1983) Neuronophagia by leukocytes in experimental spinal cord injury. J Neuropathol Exp Neurol 42:707-719.

Michalopoulos GK, DeFrances MC (1997) Liver regeneration. Science 276:60-66.

Mills CD, Hains BC, Johnson KM, Hulsebosch CE (2001) Strain and model differences in behavioral outcomes after spinal cord injury in rat. J Neurotrauma 18:743-756.

Morgenstern DA, Asher RA, Fawcett JW (2002) Chondroitin sulphate proteoglycans in the CNS injury response. Prog Brain Res 137:313-332.

Moser DM (2002) The many faces of macrophage activation. J Leukoc Biol 73:209-212.

Nesic O, Svrakic NM, Xu GY, McAdoo D, Westlund KN, Hulsebosch CE, Ye Z, Galante A, Soteropoulos P, Tolias P, Young W, Hart RP, Perez-Polo JR (2002) DNA microarray analysis of the contused spinal cord: effect of NMDA receptor inhibition. J Neurosci Res 68:406-423.

Noble LJ, Donovan F, Igarashi T, Goussev S, Werb Z (2002) Matrix metalloproteinases limit functional recovery after spinal cord injury by modulation of early vascular events. J Neurosci 22:7526-7535.

Norenberg MD, Smith J, Marcillo A (2004) The pathology of human spinal cord injury: defining the problems. J Neurotrauma 21:429-440.

O’Kane S, Ferguson MW (1997) Transforming growth factor betas and wound healing. Int J Biochem Cell Biol 29:63-78.

Pan JZ, Ni L, Sodhi A, Aguanno A, Young W, Hart RP (2002) Cytokine activity contributes to induction of inflammatory cytokine mRNAs in spinal cord following contusion. J Neurosci Res 68:315-322.

Pan JZ, Jornsten R, Hart RP (2004) Screening anti-inflammatory compounds in injured spinal cord with microarrays: a conmparison of bioinformatics analysis approaches. Physiol Genomics 17:201-214.

Popovich PG, Stokes BT, Whitacre CC (1996) Concept of autoimmunity following spinal cord injury: possible roles for T lymphocytes in the traumatized central nervous system. J Neurosci Res 45:349-363.

Popovich PG, Wei P, Stokes BT (1997) Cellular inflammatory response after spinal cord injury in Sprague-Dawley and Lewis rats. J Comp Neurol 377:443-464.

Poynton AR, Lane JM (2004) Bone healing and failure. In: Engineered bone (Petite H and Quartro R, eds), pp 81-96. Eurekah Bioscience Database. E-book available at http://www.eurekah.com.

Quencer R, Bunge R (1996) The injured spinal cord: imaging, histopathologic, clinical correlates, and basic science approaches to enhancing neural function after spinal cord injury. Spine 21:2064-2206.

Reier PJ (1986) Gliosis following CNS injury: the anatomy of astrocytic scars and their influences on axonal elongation. In: Astrocytes (Federoff S, Vernadakis A, eds), pp 263-324. Orlando, FL: Academic.

Reier PJ (2004) Cellular transplantation strategies for spinal cord injury and translational neurobiology. NeuroRx, in press.

Rolstad B (2001) The athymic nude rat: an animal experimental model to reveal novel aspects of innate immune responses? Immunol Rev 184:136-144.
Sage EH, Reed M, Funk SE, Truong T, Steadele M, Puolakkainen P, Maurice DH, Bassuk JA (2003) Cleavage of the matricellular protein SPARC by matrix metalloproteinase 3 produces polypeptides that influence angiogenesis. J Biol Chem 278:37849-37857.

Sanyal S, Kim SM, Ramaswami M (2004) Retrograde regulation in the CNS; neuron-specific interpretations of TGF-beta signaling. Neuron 41:845-848.

Schrimsher GW, Reier PJ (1992) Forelimb motor performance following cervical spinal cord contusion injury in the rat. Exp Neurol 117:287-298.

Schwartz M, Hauben E (2002) T cell-based therapeutic vaccination for spinal cord injury. Prog Brain Res 137:401-406.

Sherrat JA, Dallon JC (2002) Theoretical models of wound healing: past successes and future challenges. C R Biol 325:557-564.

Silver J, Miller JH (2004) Regeneration beyond the glial scar. Nat Rev Neurosci 5:146-156.

Singer AJ, Clark RA (1999) Cutaneous wound healing. N Engl J Med 341:738-746.

Smith LE, Kopchick JJ, Chen W, Knapp J, Kinose F, Daley D, Foley E, Smith RG, Schaeffer JM (1997) Essential role of growth hormone in ischemiainduced retinal neovascularization. Science 276:1706-1709.

Song G, Cechvala C, Resnick DK, Dempsey RJ, Rao VL (2001) GeneChip analysis after acute spinal cord injury in rat. J Neurochem 79:804-815.

Sroga JM, Jones TB, Kigerl KA, McGaughy VM, Popovich PG (2003) Rats and mice exhibit distinct inflammatory reactions after spinal cord injury. J Comp Neurol 462:223-240.

Stamenkovic I (2003) Extracellular matrix remodelling: the role of matrix metalloproteinases. J Pathol 200:448-464.

Stanisz GJ, Kecojevic A, Bronskill MJ, Henkelman RM (1999) Characterizing white matter with magnetization transfer and T2. Magn Reson Med 42:1128-1136.

Steed DL (2003) Wound-healing trajectories. Surg Clin North Am 83:547-555.

Stone JR, Collins T (2002) The role of hydrogen peroxide in endothelial proliferative responses. Endothelium 9:231-238.

Strieter RM, Kunkel SL, Arenberg DA, Burdick MD, Polverini PJ (1995) Interferon gamma-inducible protein 10 (IP-10), a member of the C-X-C chemokine family, is an inhibitor of angiogenesis. Biochem Biophys Res Commun 210:51-57.

Strutz F, Neilson EG (2003) New insights into mechanisms of fibrosis in immune renal injury. Springer Semin Immunopathol 24:459-476.

Szpaderska AM, Zuckerman JD, DiPietro LA (2003) Differential injury responses in oral mucosal and cutaneous wounds. J Dent Res 82:621-626.

Tachibana T, Noguchi K, Ruda MA (2002) Analysis of gene expression following spinal cord injury in rat using complementary DNA microarray. Neurosci Lett 327:133-137.

Tanaka EM (2003) Regeneration: if they can do it, why can't we? Cell 113:559-562.

Tang X, Davies JE, Davies SJ (2003) Changes in distribution, cell associations, and protein expression levels of NG2, neurocan, phosphacan, brevican, versican $\mathrm{V} 2$, and tenascin-C during acute to chronic maturation of spinal cord scar tissue. J Neurosci Res 71:427-444.

Taoka Y, Okajima K, Uchiba M, Murakami K, Kushimoto S, Johno M, Naruo M, Okabe H, Takatsuki K (1997) Role of neutrophils in spinal cord injury in the rat. Neuroscience 79:1177-1182.

Terai Y, Abe M, Miyamoto K, Koike M, Yamasaki M, Ueda M, Ueki M, Sato Y (2001) Vascular smooth muscle cell growth-promoting factor/Fspondin inhibits angiogenesis via the blockade of integrin alphaVbeta3 on vascular endothelial cells. J Cell Physiol 188:394-402.

Tonnesen MG, Feng X, Clark RA (2000) Angiogenesis in wound healing. J Investig Dermatol Symp Proc 5:40-46.

Tusher VG, Tibshirani R, Chu G (2001) Significance analysis of microarrays applied to the ionizing radiation response. Proc Natl Acad Sci USA 98:5116-5121.

Velardo MJ, Reier PJ, Anderson DK (2000) Spinal cord injury. In: Neurosurgery-the scientific basis of clinical practice (Crockard A, Hayward R, Hoff JT, eds), pp 499-513. Malden, MA: Blackwell Science.

Velardo MJ, Burger C, Williams PR, Baker HV, López MC, Mareci TH, White TE, Muzyczka N, Reier, PJ (2003) Transcriptional profiling of the contused spinal cord reveals a temporally orchestrated wound healing response. Soc Neurosci Abstr 29:498.3.

Venters HD, Dantzer R, Kelley KW (2000) Tumor necrosis factor-alpha 
induces neuronal death by silencing survival signals generated by the type I insulin-like growth factor receptor. Ann NY Acad Sci 917:210-220.

Walsh SV, Hopkins AM, Nusrat A (2000) Modulation of tight junction structure and function by cytokines. Adv Drug Deliv Rev 41:303-313.

Wang CX, Olschowka JA, Wrathall JR (1997) Increase of interleukin-1beta mRNA and protein in the spinal cord following experimental traumatic injury in the rat. Brain Res 759:190-196.

Webb AA, Gowribai K, Muir GD (2003a) Fischer (F-344) rats have different morphology, sensorimotor and locomotor abilities compared to Lewis, Long-Evans, Sprague-Dawley and Wistar rats. Behav Brain Res 144:143-156.

Webb S, Munro CA, Midha R, Stanisz GJ (2003b) Is multicomponent T2 a good measure of myelin content in peripheral nerve? Magn Reson Med 49:638-645.

Werner S, Grose R (2003) Regulation of wound healing by growth factors and cytokines. Physiol Rev 83:835-870.
Witte MB, Barbul A (1997) General principles of wound healing. Surg Clin North Am 77:509-529.

Xin X, Yang S, Kowalski J, Gerritsen ME (1999) Peroxisome proliferatoractivated receptor gamma ligands are potent inhibitors of angiogenesis in vitro and in vivo. J Biol Chem 274:9116-9121.

Xu JA, Hsu CY, Liu TH, Hogan EL, Perot Jr PL, Tai HH (1990) Leukotriene B4 release and polymorphonuclear cell infiltration in spinal cord injury. J Neurochem 55:907-912.

Zhou J, Schmid T, Brune B (2003) Tumor necrosis factor-alpha causes accumulation of a ubiquitinated form of hypoxia inducible factor-1alpha through a nuclear factor-kappa $\beta$-dependent pathway. Mol Biol Cell 14:2216-2225.

Zohlnhofer D, Richter T, Neumann F, Nuhrenberg T, Wessely R, Brandl R, Murr A, Klein CA, Baeuerle PA (2001) Transcriptome analysis reveals a role of interferon-gamma in human neointima formation. Mol Cell 7:1059-1069. 